\title{
Dietary supplementation of Bacillus subtilis influenced intestinal health of weaned pigs experimentally infected with a pathogenic E. coli
}

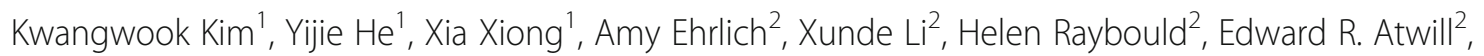
Elizabeth A. Maga', Jens Jørgensen ${ }^{3}$ and Yanhong Liu ${ }^{1 *}$

\begin{abstract}
Background: There is growing evidence to support the beneficial effects of supplementing direct-fed microbials (DFM) on performance, health status, and immune responses of weaned pigs. Therefore, the objective of this study was to investigate dietary supplementation of Bacillus subtilis (DSM 25841) on growth performance, diarrhea, gut permeability and immunity of weaned pigs experimentally infected with a pathogenic F-18 Escherichia coli (E. coli).

Results: The F18 E. coli infection reduced $(P<0.05)$ growth performance and intestinal villi height, whereas increased $(P<0.05)$ diarrhea and transcellular and paracellular permeability in the jejunum compared with non-challenged control. Supplementation of Bacillus subtilis linearly enhanced average daily gain of $E$. coli infected pigs from d 0 to 5 post-inoculation $(\mathrm{PI})(P<0.05)$ and $\mathrm{d} 0$ to $11 \mathrm{PI}(P=0.058)$. Supplementation of high dose of Bacillus subtilis reduced $(P<0.05)$ both transcellular and paracellular permeability on $\mathrm{d} 5$ and $\mathrm{d}$ $11 \mathrm{PI}$ compared with the E. coli infected pigs fed with control diet. E. coli infection up-regulated $(P<0.05)$ the mRNA expression of SLC5A10 (soluble carrier family 5 member 10) and MUC2 (mucin 2) on d 5 Pl, but down-regulated $(P<0.05)$ expression of SLC5A10, MUC2, and CLDN1 on d $11 \mathrm{PI}$ in jejunal mucosa when pigs were fed with the control diet. Supplementation of Bacillus subtilis linearly up-regulated $(P<0.05)$ the mRNA expression of CFTR and ZO1 on d 5 PI and SLC5A10 and MUC2 on d 11 PI in jejunal mucosa of E. coli infected pigs. In addition, E. coli infection increased $(P<0.05)$ the mRNA expression of several immune genes $(I L 1 A, I L 1 B$, and $I L 7$ on $d 5 \mathrm{Pl}$, and $I L 1 B, I L 6, I L 7$, and TNF on d $11 \mathrm{PI})$ in the ileal mucosa of weaned pigs. Inclusion of Bacillus subtilis to control diet linearly down-regulated gene expression of ILIA on d $5 \mathrm{PI}$ $(P=0.07)$ and IL6 on d $11 \mathrm{PI}(P<0.05)$ in ileal mucosa of $E$. coli infected pigs.
\end{abstract}

Conclusions: Supplementation of Bacillus subtilis (DSM 25841) enhanced growth rate and improved gut barrier function of weaned pigs experimentally infected with a pathogenic E. coli.

Keywords: Bacillus subtilis, Growth rate, Gut barrier function, Intestinal inflammation, Pathogenic Escherichia coli, Weaned pigs

\footnotetext{
* Correspondence: yahliu@ucdavis.edu

'Department of Animal Science, University of California, Davis, CA 95616,

USA

Full list of author information is available at the end of the article
}

(c) The Author(s). 2019 Open Access This article is distributed under the terms of the Creative Commons Attribution 4.0 International License (http://creativecommons.org/licenses/by/4.0/), which permits unrestricted use, distribution, and reproduction in any medium, provided you give appropriate credit to the original author(s) and the source, provide a link to the Creative Commons license, and indicate if changes were made. The Creative Commons Public Domain Dedication waiver (http://creativecommons.org/publicdomain/zero/1.0/) applies to the data made available in this article, unless otherwise stated. 


\section{Background}

Post-weaning diarrhea accounts for tremendous economic losses in the swine industry due to mortality and morbidity, weight loses, and cost of medication [1, 2]. Enterotoxigenic Escherichia coli (E. coli) infection is still one of the most important causes of post-weaning diarrhea in pigs. In past decades, antibiotics have been used as a powerful component to prevent post-weaning diarrhea due to $E$. coli infection. However, use of in-feed antibiotics for production purposes in the livestock industry was completely banned in USA and EU [3], which is increasing remarkably the challenges of keeping pigs healthy, especially in the post-weaning period. Thus, any reliable strategy that could enhance disease resistance and production of weaned pigs will yield substantial benefits to the industry $[4,5]$.

Direct-fed microbials (DFM), also known as probiotics are defined as "live microorganisms which, when administered in adequate amounts, confer a health benefit on the host" [6]. Direct-fed microbials are categorized into 3 main groups, including lactic acid-producing bacteria, yeast, and Bacillus [5, 7]. Growing evidence supports that the inclusion of DFM bringing various health benefits to weaned pigs by modulating gut microbiota. The benefits may include but are not limited to the inhibition of pathogen growth, improvement of nutrient digestibility and growth performance, as well as enhancement of the immunity [8-11]. In comparison to other types of DFM, Bacillus-based DFM have obvious advantages because they are spore-forming. This specific characteristic makes them thermostable for feed storage and processing (i.e., pelleting and extrusion) and successful survival at low $\mathrm{pH}$ in the stomach $[12,13]$. The potential benefits of Bacillus spp. supplementation on performance, gut health, and immunity have been reported in healthy weaned pigs or E. coli challenged pigs [14-16]. However, there is limited research focusing on the impacts of $\mathrm{Ba}$ cillus subtilis on performance and disease resistance of weaned pigs infected with F18 E. coli, which is one of major $E$. coli strains responsible for post-weaning diarrhea. Therefore, the objectives of this study were to determine the effects of a novel, specially selected strain of Bacillus subtilis (DSM 25841) on diarrhea and performance of weaned pigs experimentally infected with F18 $E$. coli, and to explore the potential modes of action of Bacillus-based DFM by investigating gut permeability, intestinal morphology, and immune responses of weaned pigs.

\section{Materials and methods}

\section{Animals, housing, experimental design, and diet}

A total of 48 weanling pigs (crossbred; initial body weight $(\mathrm{BW}): 6.73 \pm 0.77 \mathrm{~kg}$ ) with an equal number of gilts and barrows were selected from the Swine Teaching and Research Center of the University of California, Davis and used in this study. The sows and piglets used did not receive $E$. coli vaccines, antibiotic injections, or antibiotics in creep feed. Before weaning, feces were collected from sows and all their piglets destined for this study to verify the absence of $\beta$-hemolytic $E$. coli. The F18 E. coli receptor status was also tested in the piglets based on the methods of Kreuzer et al. [17]. All pigs used in this study were susceptible to F18 E. coli. After weaning, all pigs were randomly assigned to one of four dietary treatments in a randomized complete block design with body weight within sex and litter as the blocks and pig as the experimental unit. There were 12 replicate pigs per treatment. Pigs were individually housed (pen size: $0.61 \mathrm{~m} \times 1.22 \mathrm{~m}$ ) in an environmental control unit at Teaching and Research Animal Care Services at University of California, Davis for 19 days, including 7 days before and 11 days after the first $E$. coli challenge ( $\mathrm{d} 0$ ). The piglets had ad libitum access to feed and water. Environmental enrichment was provided for each pig. The light was on at 07:00 and off at 19:00 h daily in the environmental control unit.

The 4 dietary treatments included: 1) Negative control: control diet, without E. coli challenge; 2) Positive control: control diet, with $E$. coli challenge; 3) Low dose Bacillus subtilis (DSM 25841): control diet plus $1.28 \times$ $10^{9} \mathrm{CFU}$ of Bacillus subtilis/kg feed, with E. coli challenge; 4) High dose Bacillus subtilis: control diet plus $2.56 \times 10^{9} \mathrm{CFU}$ of Bacillus subtilis $/ \mathrm{kg}$ feed, with $E$. coli challenge (Table 1). Spray-dried plasma, antibiotics, and high levels of zinc oxide exceeding recommendation and normal practice were not included in the diets. The experimental diets were fed to pigs throughout the study duration. After 7 days adaptation, all pigs were orally inoculated with $3 \mathrm{~mL}$ of F18 E. coli for 3 consecutive days from d 0 post-inoculation (PI). The F18 E. coli were originally isolated from a field disease outbreak by the University of Illinois Veterinary Diagnostic Lab (isolate number: U.IL-VDL \# 05-27,242). The F18 E. coli expressed heat labile toxin (LT), heat stable toxin b (STb), and shiga-like toxin (SLT-2). The inoculums were prepared by the Western Institute for Food Safety and Security at the University of California, Davis and were provided at $10^{10} \mathrm{CFU}$ per $3 \mathrm{~mL}$ dose in phosphate buffer saline (PBS). This dose caused mild diarrhea in the current study, which is consistent with our previous published research [18-20].

\section{Clinical observations and sample collections}

The procedures for this study were adapted from previous research methods [20]. Clinical observations (diarrhea score and alertness score) were recorded twice daily throughout the study. The diarrhea score of each pig was assessed visually each day by 2 independent 
Table 1 Ingredient compositions of experimental diets ${ }^{a}$

\begin{tabular}{|c|c|}
\hline Ingredient, \% & Control diet \\
\hline Corn & 44.51 \\
\hline Dried whey & 15.00 \\
\hline Soybean meal & 14.00 \\
\hline Fish meal & 10.00 \\
\hline Soy protein concentrate & 7.00 \\
\hline Lactose & 6.00 \\
\hline Soybean oil & 2.00 \\
\hline Limestone & 0.56 \\
\hline L-Lysine.HCl & 0.15 \\
\hline DL-Methionine & 0.06 \\
\hline L-Threonine & 0.02 \\
\hline Salt & 0.40 \\
\hline Vit-mineral, Sow $6^{\mathrm{b}}$ & 0.30 \\
\hline Total & 100.00 \\
\hline \multicolumn{2}{|l|}{ Calculated energy and nutrients, as-fed } \\
\hline Metabolizable energy, kcal/kg & 3487 \\
\hline SID Lysine, \% & 1.35 \\
\hline SID Methionine, \% & 0.44 \\
\hline SID Threonine, \% & 0.79 \\
\hline SID Tryptophan, \% & 0.23 \\
\hline SID Methionine and Cysteine, \% & 0.74 \\
\hline SID Leucine, \% & 1.68 \\
\hline SID Isoleucine, \% & 0.86 \\
\hline SID Valine, \% & 0.95 \\
\hline \multicolumn{2}{|l|}{ Analyzed nutrients, \% as-fed } \\
\hline Crude protein, \% & 23.05 \\
\hline $\mathrm{Ca}, \%$ & 1.04 \\
\hline Total P, \% & 0.75 \\
\hline
\end{tabular}

${ }^{\mathrm{a}}$ Two additional diets were formulated by adding low $\left(1.28 \times 10^{9} \mathrm{CFU} / \mathrm{kg}\right)$ or high dose $\left(2.56 \times 10^{9} \mathrm{CFU} / \mathrm{kg}\right)$ of Bacillus subtilis (DSM 25841) to the control diet, respectively

${ }^{\mathrm{b}}$ Provided the following quantities of vitamins and micro minerals per kilogram of complete diet: Vitamin $A$ as retinyl acetate, $11136 \mathrm{IU}$; vitamin $\mathrm{D}_{3}$ as cholecalciferol, $2208 \mathrm{IU}$; vitamin E as DL-alpha tocopheryl acetate, $66 \mathrm{IU}$; vitamin $\mathrm{K}$ as menadione dimethylprimidinol bisulfite, $1.42 \mathrm{mg}$; thiamin as thiamine mononitrate, $0.24 \mathrm{mg}$; riboflavin, $6.59 \mathrm{mg}$; pyridoxine as pyridoxine hydrochloride, $0.24 \mathrm{mg}$; vitamin $B_{12}, 0.03 \mathrm{mg}$; $D$-pantothenic acid as $D$-calcium pantothenate, $23.5 \mathrm{mg}$; niacin, $44.1 \mathrm{mg}$; folic acid, $1.59 \mathrm{mg}$; biotin, $0.44 \mathrm{mg}$; $\mathrm{Cu}$, $20 \mathrm{mg}$ as copper sulfate and copper chloride; $\mathrm{Fe}, 126 \mathrm{mg}$ as ferrous sulfate; I, $1.26 \mathrm{mg}$ as ethylenediamine dihydriodide; $\mathrm{Mn}, 60.2 \mathrm{mg}$ as manganese sulfate; $\mathrm{Se}, 0.3 \mathrm{mg}$ as sodium selenite and selenium yeast; and $\mathrm{Zn}, 125.1 \mathrm{mg}$ as zinc sulfate

evaluators, with the score ranging from 1 to $5(1=$ normal feces, $2=$ moist feces, $3=$ mild diarrhea, $4=$ severe diarrhea, and $5=$ watery diarrhea). The frequency of diarrhea was calculated as the percentage of the pig days with a diarrhea score 3 or greater. The alertness score of each pig was assessed visually with a score from 1 to $3(1=$ normal, $2=$ slightly depressed or listless, and $3=$ severely depressed or recumbent). All pigs had alertness score 1 throughout the study, so data were not reported. Pigs were weighed on weaning day, $\mathrm{d} 0$ before inoculation, and $\mathrm{d} 5$, and 11 PI. Feed intake was recorded throughout the study. Average daily gain (ADG), average daily feed intake (ADFI), and feed efficiency (gain:feed) was calculated for each interval from d -7 to 0 , d 0 to $5 \mathrm{PI}$, and d 5 to $11 \mathrm{PI}$. Fecal samples were collected from the rectum of the 48 pigs (12 pigs/treatment) on d 0 before inoculation, d 2 and 5 PI and from the rectum of the 24 pigs (6 pigs/treatment) on d 8 and 11 PI using a fecal loop for the detection of $\beta$-hemolytic coliforms $[18,20]$. Twenty-four pigs (3 barrows and 3 gilts from each treatment) were euthanized on d 5 PI near the peak of infection, and the remaining pigs were euthanized at the end of the study (d $11 \mathrm{PI}$ ) that was the recovery period of the infection. The selection of necropsy time was based on the results of clinical observations and immune response parameters that were reported in previous published research using same $E$. coli strain and inoculation dose [18-20]. Before euthanasia, pigs were anesthetized with a $1-\mathrm{mL}$ mixture of $100 \mathrm{mg}$ telazol, $50 \mathrm{mg}$ ketamine, and $50 \mathrm{mg}$ xylazine (2:1:1) by intramuscular injection. After anesthesia, intracardiac injection with $78 \mathrm{mg}$ sodium pentobarbital (Vortech Pharmaceuticals, Ltd., Dearborn, MI) per $1 \mathrm{~kg}$ of BW was used to euthanize each pig. Fresh jejunal samples were collected in the middle of the jejunum and stored in Krebs solution for gut permeability analysis. Jejunal mucosa (the middle of jejunum) and ileal mucosa (close to the ileocecal junction) were collected and immediately stored in liquid nitrogen for gene expression analysis. Briefly, approximately $10 \mathrm{~cm}$ intestinal samples were opened longitudinally and gently rinsed with PBS to remove luminal content. Mucosa samples were collected by gently scraping samples with glass slides. Three $3-\mathrm{cm}$ segments from the duodenum, middle of the jejunum, and the ileum $(10 \mathrm{~cm}$ from the ileocecal junction) were collected and fixed in Carnoy's solution (ethanol, chloroform, and glacial acetic acid, 6:3:1 $v / v / v)$ for intestinal morphology analysis.

\section{Detection of $\beta$-hemolytic coliforms}

Briefly, fecal samples were plated on Columbia Blood Agar with 5\% sheep blood to identify hemolytic coliforms, which can lyse red blood cells surrounding the colony. Fecal samples were also plated on MacConkey agar to enumerate total coliforms. Hemolytic colonies from the blood agar were sub-cultured on MacConkey agar to confirm that they were lactose-fermenting bacteria and flat pink colonies. All plates were incubated at $37^{\circ} \mathrm{C}$ for $24 \mathrm{~h}$ in an air incubator. Populations of both total coliforms and $\beta$-hemolytic coliforms on blood agar were assessed visually, with a score from 0 to $8(0=$ no bacterial growth, $8=$ very heavy bacterial growth). The ratio of scores of $\beta$-hemolytic coliforms to total coliforms was calculated. Questionable colonies were 
sub-sub-cultured on new MacConkey and blood agar plates to verify if they were $\beta$-hemolytic $E$. coli by using triple sugar iron agar and lysine iron agar and to verify if they were F-18+ E. coli using PCR [21].

\section{Gut permeability analysis with Ussing chamber}

The procedures for gut permeability analysis followed previously published methods [22]. Tissues were mounted in an Ussing Chamber (Physiological Instruments, San Diego, CA) after being stripped of the longitudinal muscle and opened along the mesenteric border. The chamber exposed the tissue surface area $\left(0.5 \mathrm{~cm}^{2}\right)$ to $2.5 \mathrm{~mL}$ of oxygenated Krebs-mannitol $(10 \mathrm{mmol} / \mathrm{L})$ and Krebs-glucose $(10 \mathrm{mmol} / \mathrm{L})$ at $37^{\circ} \mathrm{C}$ on the luminal and serosal sides, respectively. After a 30-min period of equilibration, short circuit current and conductance were measured. Transcellular and paracellular permeability were determined by measuring the flux of horseradish peroxidase (HRP) and FITC-4000 (FD-4) across the jejunal mucosa, respectively. HRP $(0.5 \mathrm{mg})$ and FD-4 $(1 \mathrm{mg})$ were added to the mucosal chamber and $200 \mu \mathrm{L}$ of sample was collected from the serosal chamber every $30 \mathrm{~min}$ for $1 \mathrm{~h}$. To maintain a constant volume within the chambers, an equivalent volume of Krebs-glucose solution was replaced at each sample point. O-dianisidine peroxidase substrate was used to detect HRP at absorbance $450 \mathrm{~nm}$. Concentration of FD-4 was measured via fluorescence at excitation of 485 $\mathrm{nm}$ and emission of $538 \mathrm{~nm}$.

\section{Intestinal morphology}

The fixed intestinal tissues were embedded in paraffin, sectioned at $5 \mu \mathrm{m}$, and stained with high iron diamine and alcian blue. The slides were scanned by the NanoZoomer Digital Pathology System (Hamamatsu Co., Bridgewater, NJ) and all measurements were conducted in the associated slide-viewing software (NDP.view; Hamamatsu Co.) and image processing and analysis software (Image J, NIH). Fifteen straight and integrated villi and their associated crypts and surrounded area were selected to analyze villi height, crypt depth, the number of goblet cells per villus, and cross-sectional area of sulfo- and sialomucin as described by Deplancke and Gaskins [23] and Almeida et al. [19].

\section{Quantitative real-time PCR}

Total RNA were extracted from jejunal and ileal mucosa samples that were collected on d 5 and $11 \mathrm{PI}$ as in previously described [24]. The RNA quality and quantity were assessed by Agilent Bioanalyzer 2100 (Agilent, Santa Clara, CA). First-strand cDNA was produced from $1 \mu \mathrm{g}$ of total RNA per sample with SuperScript III FirstStrand Synthesis SuperMix for quantitative real timePCR (qRT-PCR) kit (Invitrogen; Carlsbad, CA) in a total volume of $20 \mu \mathrm{L}$. The mRNA expression of cystic fibrosis transmembrane conductance regulator (CFTR), claudin 1 (CLDN1), interferon gamma (IFNG), interleukin-1 alpha (IL1A), interleukin 1 beta (IL1B), interleukin 6 (IL6), interleukin-7 (IL7), mucin 2 (MUC2), occludin (OCLN), cyclooxygenase 2 (PTGS2), soluble carrier family 5 member 10 (SLC5A10), tumor necrosis factor alpha (TNF), zonula occludens-1 (ZO-1) in ileal mucosa were analyzed by qRT-PCR. Data normalization was accomplished using beta-actin $(A C T B)$ and Glyceraldehyde 3-phosphate dehydrogenase (GAPDH) as housekeeping genes. Primers were designed based on published literature and commercially synthesized by Integrated DNA Technologies, Coralville, IA. All primers were verified prior to qRT-PCR (Additional file 1: Table S1). The qRT-PCR reaction conditions followed previously published research [24]. The $2^{-\Delta \Delta C T}$ method was used to analyze relative expression of genes compared with negative control [25].

\section{Statistical analysis}

Normality of data were verified and outliers were identified for all data expect for gut permeability and frequency of diarrhea using the UNIVARIATE procedure (SAS Inst. Inc., Cary, NC). However, no outliers were detected and removed from the dataset. For growth performance, diarrhea score, gut permeability, and gene expression, data were analyzed by ANOVA using the PROC MIXED of SAS in a randomized complete block design with pig as the experimental unit. The statistical model included treatment as the main effect and blocks as random effects. Treatment means were separated by using the LSMEANS statement and the PDIFF option of PROC MIXED. Contrast statements were used to test linear and quadratic effects of Bacillus subtilis by comparing with the positive control. The chi-squared test was used for analyzing frequency of diarrhea. Statistical significance and tendency were considered at $P<0.05$ and $0.05 \leq P<0.10$, respectively.

\section{Results \\ Growth performance, diarrhea score, $\beta$-hemolytic coliforms}

No difference was observed in the initial BW of pigs among dietary treatments (Table 2). Compared with negative control pigs, pigs in the positive control group had reduced BW on d 5 PI $(P<0.05)$, lower ADG and ADFI from d 0 to 5 PI $(P<0.05)$, lower ADG from $\mathrm{d} 0$ to $11 \mathrm{PI}(P=0.057)$, and less gain:feed from d 0 to $11 \mathrm{PI}$ $(P=0.084)$. Supplementation of Bacillus subtilis linearly increased body weight $(P=0.086)$ on d 5 PI, ADG from d 0 to 5 PI $(P<0.05)$ and from d 0 to 11 PI $(P=0.058)$, compared with the positive control. No differences were observed in ADG, ADFI, and gain:feed ratio among treatment groups from d 5 to 11 PI. No differences were 
Table 2 Growth performance of weaned pigs fed diets supplemented with Bacillus subtilis

\begin{tabular}{|c|c|c|c|c|c|c|c|c|}
\hline \multirow[t]{2}{*}{ Item $^{d}$} & \multicolumn{4}{|l|}{ E. coli challenge } & \multirow[t]{2}{*}{ SEM } & \multicolumn{3}{|l|}{$P$-value } \\
\hline & Negative control & Positive control & Low dose Bacillus subtilis & High dose Bacillus subtilis & & Diet & Lin. $^{e}$ & Quad. $^{\mathrm{e}}$ \\
\hline \multicolumn{9}{|l|}{ BW, kg } \\
\hline$d-7^{f}$ & 6.76 & 6.76 & 6.64 & 6.73 & 0.23 & 0.73 & 0.82 & 0.32 \\
\hline d $0^{f}$ & 7.98 & 7.78 & 7.84 & 7.91 & 0.59 & 0.87 & 0.61 & 0.99 \\
\hline d $5 \mathrm{Pl}^{9}$ & $9.52^{\mathrm{a}}$ & $8.41^{b}$ & $8.83^{\mathrm{ab}}$ & $9.06^{\mathrm{ab}}$ & 0.60 & 0.039 & 0.086 & 0.76 \\
\hline d $11 \mathrm{Pl}^{\mathrm{g}}$ & 12.93 & 11.02 & 11.92 & 12.56 & 1.67 & 0.14 & 0.084 & 0.86 \\
\hline \multicolumn{9}{|l|}{ ADG, $g$} \\
\hline$d-7$ to $0^{f}$ & 174 & 146 & 167 & 168 & 77.33 & 0.83 & 0.50 & 0.72 \\
\hline d 0 to $5 \mathrm{Pl}^{\mathrm{f}}$ & $308^{\mathrm{a}}$ & $125^{c}$ & $193^{\mathrm{bc}}$ & $230^{\mathrm{ab}}$ & 40.79 & $<0.01$ & 0.036 & 0.71 \\
\hline d 5 to $11 \mathrm{Pl}^{\mathrm{g}}$ & 426 & 373 & 435 & 452 & 129.5 & 0.73 & 0.31 & 0.73 \\
\hline d 0 to $11 \mathrm{Pl}^{\mathrm{g}}$ & $416^{\mathrm{a}}$ & $272^{b}$ & $340^{\mathrm{ab}}$ & $375^{\mathrm{ab}}$ & 74.45 & 0.057 & 0.058 & 0.71 \\
\hline \multicolumn{9}{|l|}{ ADFI, g } \\
\hline$d-7$ to $0^{f}$ & 308 & 311 & 303 & 271 & 57.66 & 0.74 & 0.33 & 0.73 \\
\hline d 0 to $5 \mathrm{Pl}^{\mathrm{f}}$ & $572^{a}$ & $365^{b}$ & $386^{b}$ & $423^{\mathrm{ab}}$ & 58.29 & $<0.01$ & 0.21 & 0.85 \\
\hline d 5 to $11 \mathrm{Pl}^{\mathrm{g}}$ & 637 & 585 & 566 & 735 & 96.61 & 0.24 & 0.095 & 0.24 \\
\hline $\mathrm{d} 0$ to $11 \mathrm{Pl}^{\mathrm{g}}$ & 617 & 507 & 459 & 603 & 48.76 & 0.11 & 0.16 & 0.13 \\
\hline \multicolumn{9}{|l|}{$G: F$} \\
\hline$d-7$ to $0^{f}$ & 0.58 & 0.42 & 0.50 & 0.57 & 0.171 & 0.13 & 0.051 & 0.99 \\
\hline $\mathrm{d} 0$ to $5 \mathrm{Pl}^{\mathrm{f}}$ & 0.52 & 0.35 & 0.45 & 0.52 & 0.078 & 0.32 & 0.11 & 0.82 \\
\hline d 5 to $11 \mathrm{Pl}^{\mathrm{g}}$ & 0.67 & 0.61 & 0.74 & 0.60 & 0.150 & 0.47 & 0.90 & 0.14 \\
\hline $\mathrm{d} 0$ to $11 \mathrm{Pl}^{\mathrm{g}}$ & $0.68^{\mathrm{a}}$ & $0.52^{b}$ & $0.71^{\mathrm{a}}$ & $0.59^{\mathrm{ab}}$ & 0.127 & 0.084 & 0.36 & 0.034 \\
\hline
\end{tabular}

${ }^{a-c}$ Means without a common superscript are different $(P<0.05)$; bold $P$ values denote statistical significance at the $P<0.05$

${ }^{\mathrm{d}} B W$ body weight, $A D G$ average daily gain, $A D F I$ average daily feed intake, G:F gain:feed, $P I$ post inoculation

e Linear and quadratic effects of adding Bacillus subtilis to the control diet in pigs infected with F18 E. coli

Each least squares mean represents 12 observations

${ }^{g}$ Each least squares mean represents 6 observations

observed in pig BW, ADG, ADFI, and feed efficiency between negative control and high dose Bacillus subtilis diet throughout the study, with the exception that pigs in the high dose Bacillus subtilis diet had less $(P<0.05)$ ADFI from $d 0$ to 5 PI compared with the pigs in negative control group.

Compared with the negative control, F18 E. coli challenge increased $(P<0.05)$ daily diarrhea score from $d 2$ to 10 PI (Fig. 1), enhanced periodically diarrhea score from d 0 to 5 PI and d 5 to 11 PI in weaned pigs. The frequency of diarrhea (percentage of pig days with diarrhea score $\geq 3$ ) was $14.81 \%$ in negative control, $53.70 \%$ in positive control, $45.37 \%$ in low dose Bacillus subtilis, and $49.07 \%$ in high dose Bacillus subtilis group, respectively. $E$. coli challenge enhanced $(P<0.05)$ frequency of diarrhea in weaned pigs, but supplementation of Bacillus subtilis did not affect diarrhea score and frequency of diarrhea, compared with the positive control.

No $\beta$-hemolytic coliforms was detected in the feces of pigs in the negative control group (Fig. 2). Pigs in the positive control, low dose and high dose Bacillus subtilis group had higher $(P<0.05)$ percentage of $\beta$-hemolytic coliforms in feces, compared with the negative control.
No difference was observed in fecal $\beta$-hemolytic coliforms in pigs among positive control, low dose and high dose Bacillus subtilis groups, however, supplementation of Bacillus subtilis linearly increased $(P<0.05)$ the percentage of fecal $\beta$-hemolytic coliforms on d 5 and 11 PI, compared with the positive control.

\section{Gut permeability and intestinal morphology}

F18 E. coli challenge increased $(P<0.05)$ transcellular and paracellular permeability in the jejunum of weaned pigs if positive control was compared with negative control, whereas supplementation of high dose of Bacillus subtilis reduced $(P<0.05)$ jejunal permeability on $\mathrm{d} 5$ and d 11 PI, compared with the positive control (Fig. 3). Compared with the negative control, $E$. coli challenge reduced $(P<0.05)$ jejunal villi height and villi area on $\mathrm{d} 5$ PI and reduced $(P<0.05)$ duodenal villi height and crypt depth on d 11 PI (Table 3). However, supplementation of Bacillus subtilis did not affect the intestinal morphology, compared with the positive control.

E. coli challenge also reduced $(P<0.05)$ goblet cell number in duodenal villi and reduced $(P<0.05)$ sialomucin area (\%) compared with the negative control (Additional file 1: 


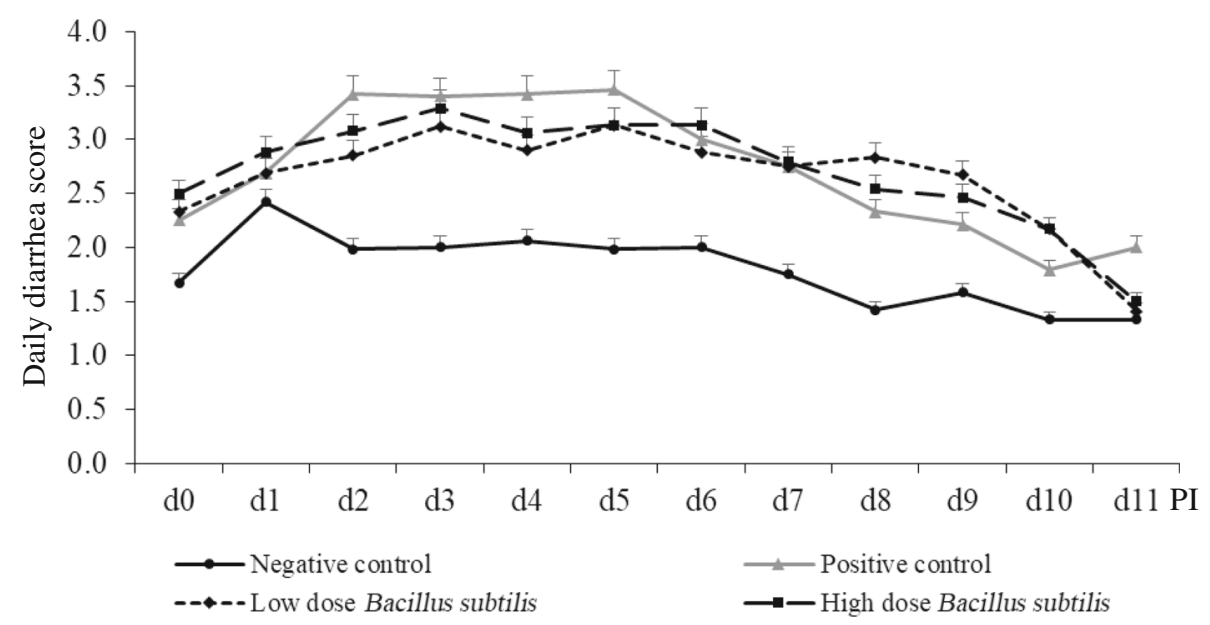

Fig. 1 Daily diarrhea score of weaned pigs fed diets supplemented with Bacillus subtilis. Diarrhea score = 1, normal feces, 2, moist feces, 3, mild diarrhea, 4, severe diarrhea, 5, watery diarrhea. Diarrhea score was lower $(P<0.05)$ in pigs fed the negative control diet, compared with all other diets from $\mathrm{d} 2$ to $\mathrm{d} 10$ post-infection (PI). No differences were observed in pigs fed with the positive control diets and the two diets supplemented with Bacillus subtilis. Each least squares mean represents 12 observations from d 0 to $\mathrm{d} 5 \mathrm{Pl}$. Each least squares mean represents 6 observations from d 6 to $\mathrm{d} 11 \mathrm{Pl}$

Table S2). Supplementation of Bacillus subtilis linearly increased $(P<0.05)$ sialomucin area along the crypts of duodenum on $\mathrm{d} 5$ PI. No differences were observed in goblet cell number, sialomucin and sulfomucin in different intestinal segments among treatments on d 11 PI.

\section{Gene expression in intestinal mucosa}

$E$. coli infection up-regulated $(P<0.05)$ the mRNA expression of SLC5A10 and MUC2 in jejunal mucosa on d 5 PI, but down-regulated $(P<0.05)$ the mRNA expression of SLC5A10, MUC2, and CLDN1 in jejunal mucosa on d 11 PI if positive control was compared with negative control (Table 4). Supplementation of high dose Bacillus subtilis up-regulated $(P<0.05)$ the mRNA expression of CFTR and ZO1 on d 5 PI and SLC5A10 expression on d $11 \mathrm{PI}$, but reduced $(P<0.05)$ MUC2 gene expression in jejunal mucosa on d $5 \mathrm{PI}$, compared with the positive control. Supplementation of low dose Bacillus subtilis down-regulated $(P<0.05) M U C 2$ gene expression on d 5 PI but increased $(P<0.05)$ MUC2 gene expression in jejunal mucosa on d $11 \mathrm{PI}$, compared with the positive control. No differences were observed

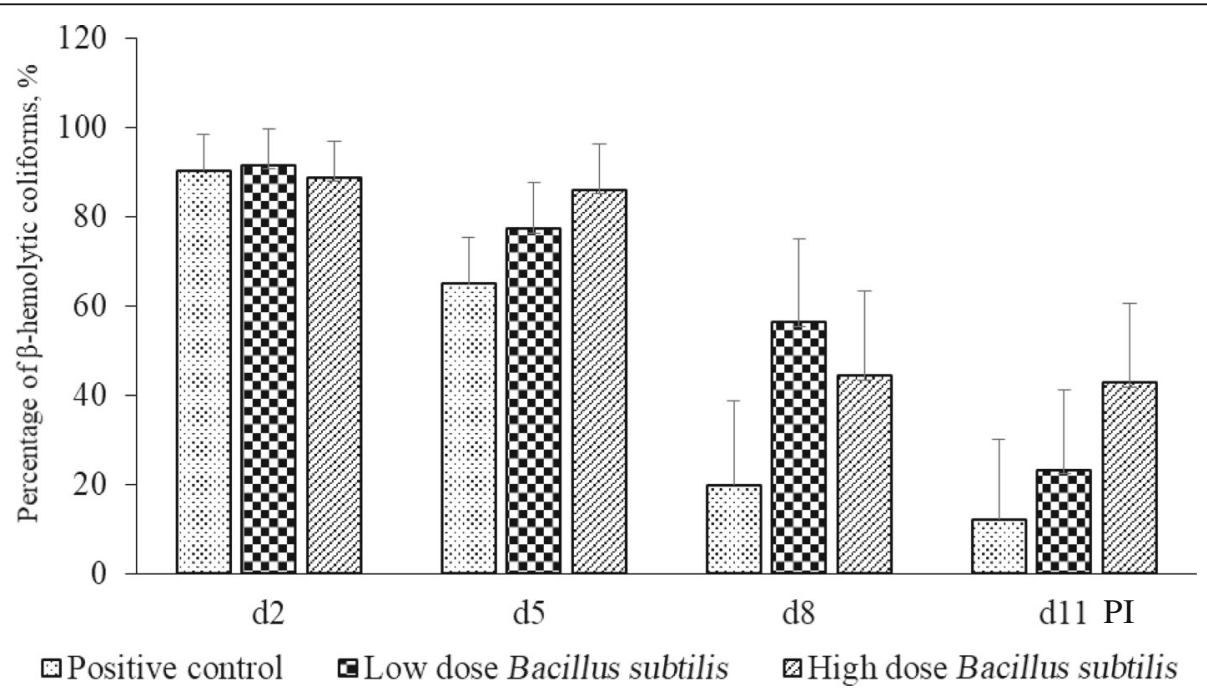

Fig. 2 The percentage of $\beta$-hemolytic coliforms in the feces of weaned pigs fed diets supplemented with Bacillus subtilis. No $\beta$-hemolytic coliforms was detected in the feces of weaned pigs in the negative control group. Supplementation of Bacillus subtilis linearly increased $(P<0.05)$ percentage of $\beta$-hemolytic coliforms (\%) in the feces of weaned pigs on $\mathrm{d} 5$ and $\mathrm{d} 11$ post-inoculation (PI). Each least squares mean represents 12 observations on $\mathrm{d} 2$ and $5 \mathrm{Pl}$, whereas each least squares mean represents 6 observations on $\mathrm{d} 8$ and $11 \mathrm{Pl}$ 

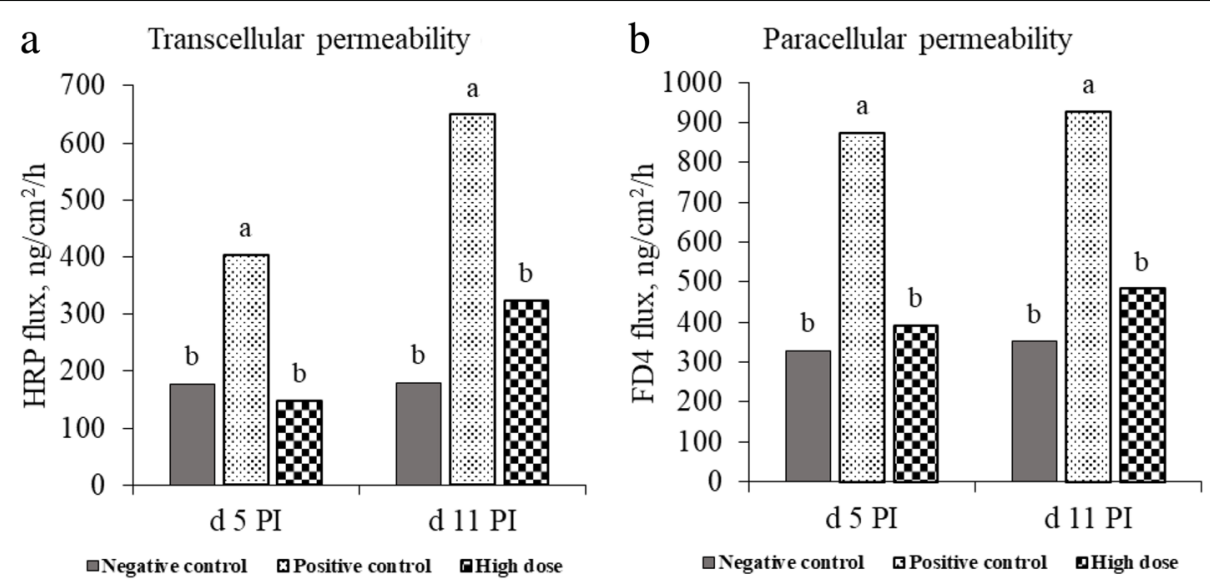

Fig. 3 Gut permeability of weaned pigs fed diets supplemented with Bacillus subtilis. a Transcellular permeability, b Paracellular permeability. The observations for east square mean were: 4 observations in negative control and 6 observations for positive control and high dose Bacillus subtilis, respectively. ${ }^{\text {a,b }}$ Means without a common superscript are different $(P<0.05)$

in the mRNA expression of OCLN in jejunal mucosa of weaned pigs among treatments on $\mathrm{d} 5$ and $11 \mathrm{PI}$.

E. coli challenge up-regulated $(P<0.05)$ the gene expression of $I L 1 A, I L 1 B$, and $I L 7$ in ileal mucosa on d 5 PI and up-regulated $(P<0.05)$ the gene expression of TNF, IL1B, IL6, and IL7 in ileal mucosa on d 11 PI if positive control was compared with negative control (Table 5). No differences were observed in the mRNA expression of immune genes among pigs in the positive control and Bacillus subtilis supplemented groups, except that supplementation of Bacillus subtilis linearly reduced $(P<0.05)$ IL6 gene expression in ileal mucosa of E. coli challenged pigs on d 11 PI.

\section{Discussion}

F18 E. coli-induced diarrhea is a common cause of morbidity and mortality in weaned pigs [26]. Results revealed in the current study indicate that supplementation of Bacillus subtilis improved growth rate, reduced gut permeability, and may modify intestinal health of weaned pigs experimentally challenged with F18 E. coli. These findings are in agreement with previous published research, showing an improvement of growth performance and health status in piglets fed different strains of Bacillus subtilis [27-29]. The potential mechanisms related to those benefits may include but are not limited to: 1) supplementation of Bacillus subtilis (DSM 25841) improved gut integrity by enhancing gut barrier function and reducing gut permeability in the jejunum; 2) supplementation of Bacillus subtilis regulated intestinal immunity of weaned pigs; 3) inclusion of Bacillus subtilis modulated the gut microbiome and their metabolites. The current experiment was focused more on the first potential mechanism.
In the present study, pigs in $E$. coli challenge groups had increased frequency of diarrhea and $\beta$-hemolytic coliforms in their feces, reduced intestinal villi, and increased gut permeability after F18 E. coli infection, compared with pigs in the negative control group. These observations are consistent with previously published research using the same $E$. coli strain [18-20, 30]. The clear clinical signs and symptoms indicated the pigs were successfully infected with F18 E. coli. The E. coli inoculum that was used in the current study expressed LT, STb, and SLT-2 toxins, which could cause villus atrophy, leaky gut, and intestinal inflammation in young pigs $[20,24,31]$. The disrupted intestinal morphology, such as reduced villus height, could decrease nutrient absorption and impair growth performance of pigs as observed in the present study [32]. Interestingly, we observed that one of sodium-dependent transporters, SLC5A10, was overexpressed in the jejunum at the peak day of F18 E. coli infection (d 5 PI), but then was down-regulated during the recovery period of $E$. coli infection (d 11 PI). The SLC5A10 encodes SGLT5, a member of the sodium/glucose transporter family. This family also contains sodium-dependent glucose transporter 1, which serves as major water pumps in the small intestine responsible for the daily intake of fluid from the normal intestine [33, 34]. It has been revealed that enteropathogenic $E$. coli infection could rapidly inactivate SGLT1 function in Caco-2 cells in vitro, which has been considered as another potential mechanism for the rapid onset of severe watery diarrhea caused by enteropathogenic E. coli [35]. However, the degree of sodium-dependent glucose transporter 1 inactivation in vivo could be impacted by many factors, including bacterial inoculum size, infection state, host age, host/bacterial genotypes, and even mucosal inflammatory response [35, 
Table 3 Intestinal morphology of weaned pigs fed diets supplemented with Bacillus subtilis

\begin{tabular}{|c|c|c|c|c|c|c|c|c|}
\hline \multirow[t]{2}{*}{ Item $^{c}$} & \multicolumn{4}{|l|}{ E. coli challenge } & \multirow[t]{2}{*}{ SEM } & \multicolumn{3}{|c|}{$P$-value } \\
\hline & Negative control & Positive control & Low dose Bacillus subtilis & High dose Bacillus subtilis & & Diet & Lin. $^{d}$ & Quad. $^{d}$ \\
\hline \multicolumn{9}{|l|}{ d $5 \mathrm{Pl}$} \\
\hline \multicolumn{9}{|l|}{ Duodenum } \\
\hline Villi height, $\mu \mathrm{m}$ & 464 & 433 & 437 & 428 & 19.73 & 0.57 & 0.86 & 0.80 \\
\hline Crypt depth, $\mu \mathrm{m}$ & 319 & 294 & 313 & 301 & 19.08 & 0.79 & 0.81 & 0.52 \\
\hline Villi height:Crypt depth & 1.46 & 1.49 & 1.40 & 1.44 & 0.058 & 0.74 & 0.56 & 0.37 \\
\hline Villi width, $\mu \mathrm{m}$ & 150 & 161 & 138 & 136 & 12.85 & 0.43 & 0.15 & 0.47 \\
\hline Villi area, $\mathrm{mm}^{2}$ & 0.066 & 0.058 & 0.059 & 0.058 & 0.004 & 0.59 & 0.99 & 0.82 \\
\hline \multicolumn{9}{|l|}{ Jejunum } \\
\hline Villi height, $\mu \mathrm{m}$ & $446^{\mathrm{a}}$ & $361^{b}$ & $370^{b}$ & $401^{\mathrm{ab}}$ & 33.58 & 0.038 & 0.18 & 0.69 \\
\hline Crypt depth, $\mu \mathrm{m}$ & 259 & 236 & 230 & 237 & 23.78 & 0.50 & 0.93 & 0.71 \\
\hline Villi height:Crypt depth & 1.74 & 1.54 & 1.62 & 1.70 & 0.123 & 0.49 & 0.26 & 0.99 \\
\hline Villi width, $\mu \mathrm{m}$ & 110 & 109 & 110 & 108 & 3.41 & 0.98 & 0.88 & 0.74 \\
\hline Villi area, $\mathrm{mm}^{2}$ & $0.054^{\mathrm{a}}$ & $0.038^{\mathrm{b}}$ & $0.039^{b}$ & $0.041^{b}$ & 0.004 & 0.042 & 0.60 & 0.91 \\
\hline \multicolumn{9}{|l|}{ Ileum } \\
\hline Villi height, $\mu \mathrm{m}$ & 375 & 372 & 355 & 359 & 17.71 & 0.56 & 0.43 & 0.45 \\
\hline Crypt depth, $\mu \mathrm{m}$ & 206 & 222 & 219 & 213 & 8.90 & 0.46 & 0.39 & 0.85 \\
\hline Villi height:Crypt depth & 1.82 & 1.68 & 1.61 & 1.68 & 0.054 & 0.082 & 0.95 & 0.36 \\
\hline Villi width, $\mu \mathrm{m}$ & 115 & 114 & 117 & 109 & 6.37 & 0.85 & 0.58 & 0.53 \\
\hline Villi area, $\mathrm{mm}^{2}$ & 0.042 & 0.041 & 0.037 & 0.038 & 0.003 & 0.37 & 0.45 & 0.33 \\
\hline \multicolumn{9}{|l|}{ d $11 \mathrm{PI}$} \\
\hline \multicolumn{9}{|l|}{ Duodenum } \\
\hline Villi height, $\mu \mathrm{m}$ & $511^{\mathrm{a}}$ & $402^{b}$ & $439^{b}$ & $436^{b}$ & 32.75 & 0.015 & 0.28 & 0.46 \\
\hline Crypt depth, $\mu \mathrm{m}$ & $388^{\mathrm{a}}$ & $330^{b}$ & $314^{\mathrm{b}}$ & $319^{b}$ & 39.50 & 0.012 & 0.62 & 0.58 \\
\hline Villi height:Crypt depth & 1.33 & 1.23 & 1.41 & 1.37 & 0.077 & 0.17 & 0.091 & 0.14 \\
\hline Villi width, $\mu \mathrm{m}$ & 159 & 163 & 142 & 139 & 9.53 & 0.086 & 0.039 & 0.31 \\
\hline Villi area, $\mathrm{mm}^{2}$ & 0.077 & 0.073 & 0.064 & 0.079 & 0.019 & 0.84 & 0.74 & 0.43 \\
\hline \multicolumn{9}{|l|}{ Jejunum } \\
\hline Villi height, $\mu \mathrm{m}$ & 448 & 405 & 385 & 441 & 25.80 & 0.14 & 0.22 & 0.16 \\
\hline Crypt depth, $\mu \mathrm{m}$ & 269 & 252 & 248 & 254 & 14.51 & 0.76 & 0.93 & 0.78 \\
\hline Villi height:Crypt depth & 1.70 & 1.61 & 1.55 & 1.74 & 0.086 & 0.40 & 0.28 & 0.24 \\
\hline Villi width, $\mu \mathrm{m}$ & 122 & 111 & 112 & 115 & 4.40 & 0.31 & 0.55 & 0.77 \\
\hline Villi area, $\mathrm{mm}^{2}$ & 0.054 & 0.045 & 0.042 & 0.052 & $<0.01$ & 0.077 & 0.17 & 0.16 \\
\hline \multicolumn{9}{|l|}{ Ileum } \\
\hline Villi height, $\mu \mathrm{m}$ & 405 & 344 & 391 & 369 & 28.86 & 0.17 & 0.38 & 0.16 \\
\hline Crypt depth, $\mu \mathrm{m}$ & 229 & 203 & 237 & 224 & 13.30 & 0.32 & 0.27 & 0.16 \\
\hline Villi height:Crypt depth & 1.77 & 1.70 & 1.67 & 1.65 & 0.088 & 0.62 & 0.65 & 0.94 \\
\hline Villi width, $\mu \mathrm{m}$ & 128 & 120 & 122 & 126 & 6.26 & 0.92 & 0.53 & 0.95 \\
\hline Villi area, $\mathrm{mm}^{2}$ & 0.047 & 0.040 & 0.047 & 0.045 & $<0.01$ & 0.47 & 0.35 & 0.31 \\
\hline
\end{tabular}

a,b Means without a common superscript are different $(P<0.05)$; bold $P$ values denote statistical significance at the $P<0.05$

${ }^{\mathrm{C}}$ Each least squares mean represents 6 observations. $P$ l post-inoculation

${ }^{d}$ Linear and quadratic effects of adding Bacillus subtilis to the control diet in pigs infected with F18 E. coli

36]. There are limited research reported on SLC5A10 status in the small intestine of weaned pigs because it is not the major glucose transporter in the small intestine. More research may be needed to explore the specific roles of SLC5A10 and other members in the same sodium/glucose cotransporter family in F18 E. coli infection. 
Table 4 The relative mRNA expression of genes in jejunal mucosa of weaned pigs fed diets supplemented with Bacillus subtilis

\begin{tabular}{|c|c|c|c|c|c|c|c|c|}
\hline \multirow[t]{2}{*}{ Item $^{c}$} & \multicolumn{4}{|l|}{ E. coli challenge } & \multirow[t]{2}{*}{ SEM } & \multicolumn{3}{|l|}{$P$-value } \\
\hline & Negative control & Positive control & Low dose Bacillus subtilis & High dose Bacillus subtilis & & Diet & Lin. $^{d}$ & Quad. \\
\hline \multicolumn{9}{|l|}{ d $5 \mathrm{Pl}$} \\
\hline CFTR & $1.00^{\mathrm{b}}$ & $0.99^{\mathrm{b}}$ & $1.36^{\mathrm{ab}}$ & $2.57^{\mathrm{a}}$ & 0.43 & $<0.05$ & $<0.05$ & 0.52 \\
\hline CLDN1 & 1.00 & 0.60 & 1.41 & 1.81 & 0.62 & 0.45 & 0.09 & 0.73 \\
\hline MUC2 & $1.00^{\mathrm{b}}$ & $2.58^{\mathrm{a}}$ & $0.87^{\mathrm{b}}$ & $1.37^{\mathrm{b}}$ & 0.27 & 0.08 & $<0.05$ & $<0.05$ \\
\hline OCLN & 1.00 & 1.14 & 1.17 & 1.65 & 0.33 & 0.33 & 0.08 & 0.47 \\
\hline SLC5A10 & $1.00^{b}$ & $2.41^{\mathrm{a}}$ & $1.69^{\mathrm{ab}}$ & $1.82^{\mathrm{ab}}$ & 0.37 & $<0.05$ & 0.33 & 0.38 \\
\hline $\mathrm{ZO1}$ & $1.00^{\mathrm{b}}$ & $0.78^{b}$ & $1.33^{\mathrm{ab}}$ & $2.15^{\mathrm{a}}$ & 0.45 & $<0.05$ & $<0.05$ & 0.77 \\
\hline \multicolumn{9}{|l|}{ d $11 \mathrm{PI}$} \\
\hline CFTR & 1.00 & 0.60 & 0.81 & 0.87 & 0.22 & 0.65 & 0.41 & 0.80 \\
\hline CLDN1 & $1.00^{\mathrm{a}}$ & $0.49^{b}$ & $0.65^{a b}$ & $0.61^{\mathrm{ab}}$ & 0.15 & $<0.05$ & 0.56 & 0.57 \\
\hline MUC2 & $1.00^{\mathrm{a}}$ & $0.39^{b}$ & $0.88^{\mathrm{a}}$ & $0.76^{\mathrm{ab}}$ & 0.21 & $<0.05$ & $<0.05$ & $<0.05$ \\
\hline OCLN & 1.00 & 0.64 & 1.33 & 1.24 & 0.31 & 0.52 & 0.23 & 0.33 \\
\hline SLC5A10 & $1.00^{\mathrm{a}}$ & $0.29^{b}$ & $0.62^{\mathrm{ab}}$ & $0.86^{\mathrm{a}}$ & 0.16 & $<0.05$ & $<0.05$ & 0.77 \\
\hline 201 & 1.00 & 0.68 & 1.10 & 0.78 & 0.24 & 0.62 & 0.78 & 0.24 \\
\hline
\end{tabular}

$\overline{\mathrm{a}, \mathrm{b}}$ Means without a common superscript are different $(P<0.05)$; bold $P$ values denote statistical significance at the $P<0.05$

'Each least squares mean represents 6 observations. PI post-inoculation. CFTR cystic fibrosis transmembrane conductance regulator; CLDN1 Claudin 1; MUC2 Mucin-2; OCLN Occludin; SLC5A10 soluble carrier family 5 member 10; ZO1 Zonula occludens-1

${ }^{\mathrm{d}}$ Linear and quadratic effects of adding Bacillus subtilis to the control diet in pigs infected with F18 E. coli

Table 5 The relative mRNA expression of genes in ileal mucosa of weaned pigs fed diets supplemented with Bacillus subtilis

\begin{tabular}{|c|c|c|c|c|c|c|c|c|}
\hline \multirow[t]{2}{*}{ Item $^{c}$} & \multicolumn{4}{|l|}{ E. coli challenge } & \multirow[t]{2}{*}{ SEM } & \multicolumn{3}{|l|}{$P$-value } \\
\hline & Negative control & Positive control & Low dose Bacillus subtilis & High dose Bacillus subtilis & & Diet & Lin. $^{d}$ & Quad. \\
\hline \multicolumn{9}{|l|}{ d $5 \mathrm{Pl}$} \\
\hline IFNG & 1.00 & 1.25 & 1.14 & 0.75 & 0.26 & 0.44 & 0.14 & 0.60 \\
\hline ILIA & $1.00^{\mathrm{b}}$ & $1.98^{\mathrm{a}}$ & $1.47^{\mathrm{ab}}$ & $1.13^{\mathrm{ab}}$ & 0.28 & $<0.05$ & 0.07 & 0.82 \\
\hline$I L 1 B$ & $1.00^{\mathrm{b}}$ & $4.40^{\mathrm{a}}$ & $2.79^{a b}$ & $3.25^{\mathrm{a}}$ & 0.82 & $<0.05$ & 0.28 & 0.24 \\
\hline IL6 & 1.00 & 0.99 & 1.00 & 1.10 & 0.16 & 0.95 & 0.62 & 0.83 \\
\hline IL7 & $1.00^{\mathrm{b}}$ & $4.83^{\mathrm{a}}$ & $2.97^{\mathrm{ab}}$ & $3.42^{\mathrm{a}}$ & 1.10 & $<0.05$ & 0.20 & 0.22 \\
\hline MUC2 & 1.00 & 1.53 & 2.04 & 1.69 & 0.32 & 0.23 & 0.76 & 0.37 \\
\hline PTGS2 & 1.00 & 1.07 & 1.12 & 1.00 & 0.05 & 0.29 & 0.35 & 0.19 \\
\hline TNFA & $1.00^{\mathrm{b}}$ & $1.92^{\mathrm{ab}}$ & $1.24^{\mathrm{ab}}$ & $2.06^{\mathrm{a}}$ & 0.31 & $<0.05$ & 0.78 & 0.07 \\
\hline \multicolumn{9}{|l|}{ d $11 \mathrm{Pl}$} \\
\hline IFNG & 1.00 & 2.33 & 1.41 & 1.35 & 0.68 & 0.50 & 0.28 & 0.56 \\
\hline ILIA & 1.00 & 1.92 & 1.69 & 1.20 & 0.47 & 0.52 & 0.32 & 0.82 \\
\hline $\operatorname{ILIB}$ & $1.00^{b}$ & $3.32^{\mathrm{a}}$ & $1.59^{\mathrm{ab}}$ & $3.83^{\mathrm{a}}$ & 0.99 & $<0.05$ & 0.73 & 0.13 \\
\hline IL6 & $1.00^{b}$ & $1.89^{\mathrm{a}}$ & $0.72^{b}$ & $0.64^{b}$ & 0.22 & $<0.05$ & $<0.05$ & 0.09 \\
\hline IL7 & $1.00^{b}$ & $3.56^{\mathrm{a}}$ & $2.37^{\mathrm{ab}}$ & $4.00^{\mathrm{a}}$ & 1.00 & $<0.05$ & 0.78 & 0.27 \\
\hline MUC2 & 1.00 & 1.61 & 2.30 & 2.35 & 0.54 & 0.27 & 0.35 & 0.64 \\
\hline PTGS2 & 1.00 & 1.19 & 1.12 & 1.14 & 0.06 & 0.26 & 0.64 & 0.61 \\
\hline TNFA & $1.00^{\mathrm{b}}$ & $3.46^{\mathrm{a}}$ & $1.94^{\mathrm{ab}}$ & $3.42^{\mathrm{a}}$ & 1.24 & $<0.05$ & 0.97 & 0.12 \\
\hline
\end{tabular}

a,b Means without a common superscript are different $(P<0.05)$; bold $P$ values denote statistical significance at the $P<0.05$

${ }^{c}$ Each least squares mean represents 6 observations. PI post-inoculation, IFNG Interferon gamma; IL IA Interleukin-1 alpha, IL1B Interleukin 1 beta, IL6 Interleukin 6 , IL7 Interleukin-7, MUC2 Mucin 2, PTGS2 Cyclooxygenase 2, TNF Tumor necrosis factor alpha

dLinear and quadratic effects of adding Bacillus subtilis to the control diet in pigs infected with F18 E. coli 
As one of many potential candidates to partially replace in-feed antibiotics, Bacillus subtilis have attracted much attention as they are thermostable during feed processing and they are able to deliver their potential benefits to the small/large intestine after surviving at low $\mathrm{pH}$ in stomach [5]. The reported effects of Bacillus subtilis on the incidence of diarrhea in weaned pigs are inconsistent. As an example, Bhandari et al. [37] and $\mathrm{Hu}$ et al. [15] revealed that addition of Bacillus subtilis reduced diarrhea of weaned pigs either in a K88 E. coli challenge study or in a normal housing condition, but this was not the case in the research reported by Giang et al. [38]. Although supplementation of Bacillus subtilis did not reduce frequency of diarrhea in E. coli challenged pigs in the present study, it did enhance growth rate and feed efficiency of weaned pigs after $E$. coli infection. These observations clearly indicate that addition of Bacillus subtilis promoted weaned pig performance probably through other mechanisms. A follow-up experiment is being conducted to explore the correlation between gut permeability and overall diarrhea score by adding more sampling points and extending experimental period.

Tight junction proteins, such as ZO1, Occludin, and Claudin, are critical in the maintenance of intestinal integrity and barrier function [39]. Growing evidence suggests that the expression of intestinal tight junction proteins is oppositely correlated with gut permeability [40]. Thus, the first potential mode of action for Bacillus subtilis supplementation was that it may enhance intestinal integrity and reduce nutrient loss of weaned pigs during bacterial infection $[41,42]$. In the present study, it has been confirmed that supplementation of Bacillus subtilis reduced transcellular and paracellular permeability and enhanced gene expression of $Z O 1$ in the jejunum of $E$. coli infected pigs. Similar findings were also reported in vitro by $\mathrm{Gu}$ et al. [43], in which Bacillus subtilis decreased permeability of tight junction and improved expression of ZO-1 and occludin in a porcine epithelial cell line. Bacillus subtilis was also observed to enhance the gene expression of tight junction proteins in mice with inflammatory bowel disease [44]. Cystic fibrosis transmembrane conductance regulator (CFTR), a cAMP-activated anion channel, is very important in regulating the secretion of chloride and bicarbonate ions during E. coli infection $[45,46]$. It has also been reported that the up-regulation of CFTR and its mediated bicarbonate ion secretion was highly involved in bacterial killing and host defense mechanism [47]. In the current experiment, supplementation of Bacillus subtilis enhanced CFTR expression in jejunal mucosa of E. coli infected pigs on d 5 PI, indicating this Bacillus strain may enhance host defense that was concomitant with better performance. However, the regulatory role of CFTR has to be confirmed in future research.
Mucins are secreted by goblet cells and are classified into neutral, sulfate (sulfo-), and acidic (sialo-) mucins [48]. Goblet cell number and mucin production may be impacted by intestinal infections as a protective mechanism [49]. In the present study, E. coli infected pigs had reduced goblet cell number in duodenum on d 5 PI during the peak of infection, but this was not the case on $d$ $11 \mathrm{PI}$ as pigs recovered from the infection. Although no differences were observed in mucin percentage in the crypts of the jejunum and ileum based on histological analysis, pigs infected with F18 E. coli had increased $M U C 2$ gene expression during the peak of infection but decreased $M U C 2$ expression during the recovery period. These observations confirmed the role of mucin as the first line of host response against F18 E. coli infection [50]. The effects of Bacillus subtilis on intestinal mucin production are limited, with the exception that supplementation of Bacillus subtilis increased the percentage of sialomucin in the duodenum of weaned pigs on d 5 PI. However, supplementation of Bacillus subtilis oppositely impacted $M U C 2$ expression in jejunal mucosa of $E$. coli infected pigs compared with positive control, and the mRNA expression of $M U C 2$ gene in jejunal mucosa of weaned pigs was not different among Bacillus subtilis groups compared with the negative control. These results indicate that pigs supplemented with Bacillus subtilis may have less severe E. coli infection compared with pigs in the positive control.

Supplementation of Bacillus-based DFM have been reported to enhance intestinal mucosa immunity in both pre-weaning and post-weaning pigs, by regulating the population of intraepithelial lymphocytes and/or the production of secretory IgA [51-53]. In the present study, supplementation of Bacillus subtilis had limited effects on the expression of several immune genes involved in intestinal inflammation except that IL6 expression was down-regulated by feeding Bacillus subtilis on d 11 PI. In addition, pigs supplemented with low dose Bacillus subtilis had similar mRNA expression of several other inflammatory mediators (i.e. TNF, IL1B, and IL7) in the ileal mucosa, compared with pigs that were not infected with E. coli. Results of $M U C 2$ and immune gene expression suggest that pigs supplemented with Bacillus subtilis may have less severe of intestinal inflammation induced by $E$. coli infection, comparison with infected pigs fed with the control diet. However, more measurements are suggested in the future research to confirm this potential effects, for example, including an additional sampling point (i.e. d 2 PI) after E. coli inoculation to focus on exploring intestinal immunity, or analyzing protein concentrations of inflammatory mediators in ileal mucosa of weaned pigs.

Other potential mechanisms may also be related to the enhanced growth rate by feeding Bacillus subtilis. As an 
example, Bacillus-based DFM may enhance growth performance of weaned pigs by improving digestibility of energy and nutrients [29, 54]. In particular, Bacillus-based DFM may increase fiber degradation in the intestinal tract of pigs [11, 55]. Bacillus-based DFM supplementation may also increase the population of beneficial microorganisms in the intestinal tract, which compete nutrients and attachment sites with pathogens, therefore, reducing the proliferation of pathogens [56]. Further research is necessary to examine the potential modes of action listed here.

\section{Conclusion}

Dietary intervention on weaned pig intestinal health and performance is complicated by targeting different areas, which includes but is not limited to strengthening gut integrity and enhancing nutrient digestion and absorption, a balanced intestinal immunity, and a favorable intestinal microflora. It is important to keep in mind that it is difficult to cover the majority of areas with one single dietary change. Results of this study indicate that in feed supplementation of Bacillus subtilis (DSM 25841) enhanced the growth rate of F18 $E$. coli infected pigs by enhancing gut integrity and decreasing gut permeability. However, no clear reduction of diarrhea and fecal $\beta$-hemolytic coliforms was observed in pigs supplemented with Bacillus subtilis. Feeding Bacillus subtilis may also impact intestinal inflammation of $E$. coli infected pigs. In conclusion, the present study indicates that supplementation of Bacillus subtilis in animal feed could improve gut barrier function and modify immunity of weaned pigs, which may further promote weaned pig growth performance and increase profitability of pork producers as the use of antibiotics in feed is restricted. The current study has demonstrated the great potential of Bacillus subtilis, more research will be further conducted to confirm this potential and to further explore the underlying mechanisms.

\section{Additional file}

Additional file 1: Table S1. Gene-specific primer sequences and PCR conditions $^{1}$. Table S2. Goblet cell number in the small intestine and relative amounts of sulfo- and sialomucin area (\%) of weaned pigs fed diets supplemented with Bacillus subtilis (DOCX $22 \mathrm{~kb}$ )

\footnotetext{
Abbreviations

ACTB: $\beta$-actin; ADFI: Average daily feed intake; ADG: Average daily gain; CFTR: Cystic fibrosis transmembrane conductance regulator; CLDN1: Claudin 1; DFM: Direct-fed microbials; E. coli: Escherichia coli; GAPDH: Glyceraldehyde 3-phosphate dehydrogenase; IFNG: Interferon-gamma; IL: Interleukin; LT: Heat-labile toxin; mRNA: Messenger RNA; MUC2: Mucin 2; OCLN: Occludin; PBS: Phosphate buffer saline; PI: Post-inoculation; PTGS2: Cyclooxygenase 2; SGLT1: Sodium-dependent glucose transporter 1; SLC5A10: Soluble carrier family 5 member 10; ST: Heat-stable toxin; STL2: Shiga-like toxin; TNF: Tumor necrosis factor alpha; ZO1: Zona occludens-1
}

Acknowledgments

Not applicable.

\section{Funding}

This project was supported by Chr. Hansen A/S, Hoersholm, Denmark and the United States Department of Agriculture (USDA) National Institute of Food and Agriculture, multistate project W3002.

\section{Availability of data and materials}

All data generated or analyzed during this study are available from the corresponding author upon reasonable request.

\section{Authors' contributions}

The contributions of the authors were as follows: KK conducted the animal work and most of the laboratory work and wrote most of the manuscript. $\mathrm{YH}, \mathrm{XX}$, and $\mathrm{AE}$. helped to conduct animal trial and part of the laboratory work. $X L, H R, E R A, E M$, and JJ provided labs and staffs for helping the animal work and part of the laboratory work and helped to revise the manuscript. $Y L$ was the principle investigator. She designed the experiment, oversaw the development of the study and wrote the last version of the manuscript. The authors declare no conflicts of interest. All authors read and approved the final manuscript.

\section{Ethics approval and consent to participate}

The protocol for this study was reviewed and approved by the Institutional Animal Care and Use Committee at the University of California, Davis. The study was conducted at the Teaching and Research Animal Care Services (TRACS) P building at the University of California, Davis.

\section{Consent for publication}

Not applicable.

\section{Competing interests}

The authors declare that they have no competing interests.

\section{Author details}

${ }^{1}$ Department of Animal Science, University of California, Davis, CA 95616, USA. ${ }^{2}$ School of Veterinary Medicine, University of California, Davis, CA 95616, USA. ${ }^{3}$ Chr. Hansen A/S, Hoersholm, Denmark.

Received: 17 January 2019 Accepted: 10 May 2019

Published online: 25 June 2019

\section{References}

1. Fairbrother JM, Nadeau É, Gyles CL. Escherichia coli in postweaning diarrhea in pigs: an update on bacterial types, pathogenesis, and prevention strategies. Anim Health Res Rev. 2005;6:17-39.

2. Nagy B, Fekete PZ. Enterotoxigenic Escherichia coli in veterinary medicine. Int J Med Microbiol. 2005;295:443-54.

3. FDA (Food and Drug Administration). 2016. New animal drugs and new animal drug combination products administered in or on medicated feed or drinking water of food-producing animals: recommendations for drug sponsors for voluntarily aligning product use conditions with GFI \#209. FDA Guidance for Industry \#213. https://www.fda.gov/downloads/ AnimalVeterinary/GuidanceComplianceEnforcement/Guidanceforlndustry/ UCM299624.pdf. Accessed 10 May 2018.

4. Pettigrew JE. Reduced use of antibiotic growth promoters in diets fed to weanling pigs: dietary tools, part 1. Anim Biotechnol. 2006;17:207-15.

5. Liu Y, Espinosa CD, Abelilla JJ, Casas GA, Lagos LV, Lee SA, et al. Non-antibiotic feed additives in diets for pigs: a review. Anim Nutr. 2018;4:113-25.

6. World Health Organization (WHO). Health and nutritional properties of probiotics in food including powder milk with live lactic acid bacteria. FAO/ WHO. 2001

7. National Research Council (NRC). Nutrient requirements of swine: eleventh revised edition. Washington, DC: The National Academies Press; 2012. https://doi.org/10.17226/13298.

8. Huang C, Qiao S, Li D, Piao X, Ren J. Effects of Lactobacilli on the performance, diarrhea incidence, VFA concentration and gastrointestinal microbial flora of weaning pigs. Asian Australas J Anim Sci. 2004;17:401-9. 
9. Le Bon M, Davies HE, Glynn C, Thompson C, Madden M, Wiseman J, et al. Influence of probiotics on gut health in the weaned pig. Livest Sci. 2010; 133:179-81.

10. Cho JH, Zhao PY, Kim H. Probiotics as a dietary additive for pigs: a review. J Anim Vet Adv. 2011;10:2127-34.

11. Kenny M, Smidt H, Mengheri E, Miller B. Probiotics-do they have a role in the pig industry? Animal. 2011;5:462-70.

12. Barbosa TM, Serra CR, La Ragione RM, Woodward MJ, Henriques AO. Screening for Bacillus isolates in the broiler gastrointestinal tract. Appl Environ Microbiol. 2005;71:968-78.

13. Cutting SM. Bacillus probiotics. Food Microbiol. 2011;28:214-20.

14. Guo X, Li D, Lu W, Piao X, Chen X. Screening of Bacillus strains as potential probiotics and subsequent confirmation of the in vivo effectiveness of Bacillus subtilis MA139 in pigs. Antonie van Leeuwenhoek. Int J Gen Mol Microbiol. 2006;90:139-46.

15. Hu Y, Dun Y, Li S, Zhao S, Peng N, Liang Y. Effects of Bacillus subtilis KN-42 on growth performance, diarrhea and faecal bacterial flora of weaned piglets. Asian Australas J Anim Sci. 2014;27:1131-40.

16. Zhou D, Zhu YH, Zhang W, Wang ML, Fan WY, Song D, et al. Oral administration of a select mixture of Bacillus probiotics generates $\operatorname{Tr} 1$ cells in weaned F4ab/acR ${ }^{-}$pigs challenged with an $\mathrm{F}^{+}$ETECNTEC/EPEC strain. Vet Res. 2015;46:95.

17. Kreuzer S, Reissmann M, Brockmann GA. New fast and cost-effective gene test to get the ETEC F18 receptor status in pigs. Vet Microbio. 2013;163:392-4

18. Song M, Liu Y, Soares JA, Che TM, Osuna O, Maddox CW, et al. Dietary clays alleviate diarrhea of weaned pigs. J Anim Sci. 2012;90:345-60

19. Almeida JAS, Liu Y, Song M, Lee JJ, Gaskins HR, Maddox CW, et al. Escherichia coli challenge and one type of smectite alter intestinal barrier of pigs. J Anim Sci Biotechnol. 2013;4:52.

20. Liu Y, Song M, Che TM, Almeida JAS, Lee JJ, Bravo D, et al. Dietary plant extracts alleviate diarrhea and alter immune responses of weaned pigs experimentally infected with a pathogenic Escherichia coli. J Anim Sci. 2013; 91:5294-306.

21. DebRoy C, Maddox CW. Identification of virulence attributes of gastrointestinal Escherichia coli isolates of veterinary significance. Anim Health Res Rev. 2001;2:129-40.

22. Garas LC, Feltrin C, Kristina Hamilton M, Hagey JV, Murray JD, Bertolini LR, et al. Milk with and without lactoferrin can influence intestinal damage in a pig model of malnutrition. Food Funct. 2016;7:665-78.

23. Deplancke B, Gaskins HR. Microbial modulation of innate defense: goblet cells and the intestinal mucus layer. Am J Clin Nutr. 2001;73:1131-41.

24. Liu Y, Song M, Che TM, Lee JJ, Bravo D, Maddox CW, et al. Dietary plant extracts modulate gene expression profiles in ileal mucosa of weaned pigs after an Escherichia coli infection. J Anim Sci. 2014;92:2050-62.

25. Livak KJ, Schmittgen TD. Analysis of relative gene expression data using realtime quantitative $P C R$ and the 2- $\Delta \Delta C T$ method. Methods. 2001;25:402-8.

26. Verdonck F, Cox E, Van Gog K, Van der Stede Y, Duchateau L, Deprez P, et al. Different kinetic of antibody responses following infection of newly weaned pigs with an F4 enterotoxigenic Escherichia coli strain or an F18 verotoxigenic Escherichia coli strain. Vaccine. 2002;20:2995-3004

27. Alexopoulos C, Georgoulakis IE, Tzivara A, Kyriakis CS, Govaris A, Kyriakis SC Field evaluation of the effect of a probiotic-containing Bacillus licheniformis and Bacillus subtilis spores on the health status, performance, and carcass quality of grower and finisher pigs. J Vet Med Ser A Physiol Pathol Clin Med. 2004;51:306-12.

28. Wang SP, Yang L, Tang XS, Cai LC, Liu G, Kong XF, et al. Dietary supplementation with high-dose Bacillus subtilis or Lactobacillus reuter modulates cellular and humoral immunities and improves performance in weaned piglets. J Food Agric Environ. 2011;9:181-7.

29. Lee SH, Ingalev SL, Kim JS, Kim KH, Lokhande A, Kwon IK, et al. Effects of supplementation of Bacillus subtilis LS 1-2 grown on citrus-juice waste and corn-soybean meal substrate on performance and gut health of weaning pigs. Anim Nutr Feed Technol. 2014;14:225.

30. Kim K, Ehrlich A, Perng V, Chase JA, Raybould H, Li X, et al. Algae-derived $\beta$ glucan enhanced gut health and immune responses of weaned pigs experimentally infected with a pathogenic E. coli. Anim Feed Sci Technol. 2019;248:114-25

31. Rose R, Whipp SC, Moon HW. Effects of Escherichia coli heat-stable enterotoxin $b$ on small intestinal villi in pigs, rabbits, and lambs. Vet Pathol. 1987:24:71-9.
32. Nabuurs MJA, Hoogendoorn A, Van Der Molen EJ, Van Osta ALM. Villus height and crypt depth in weaned and unweaned pigs, reared under various circumstances in the Netherlands. Res Vet Science. 1993;55:78-84.

33. Meinild A-K, Klaerke DA, Loo DDF, Wright EM, Zeuthen T. The human $\mathrm{Na}^{+}$ - glucose cotransporter is a molecular water pump. J Physiol. 1998;508:15-21.

34. Wood IS, Trayhurn P. Glucose transporters (GLUT and SGLT): expanded families of sugar transport proteins. Br J Nutr. 2003:89:3-9.

35. Dean P, Maresca M, Sch ller S, Phillips AD, Kenny B. Potent diarrheagenic mechanism mediated by the cooperative action of three enteropathogenic Escherichia coli-injected effector proteins. Proc Natl Acad Sci. 2006;103:1876-81.

36. Das S, Jayaratne R, Barrett KE. The role of ion transporters in the pathophysiology of infectious diarrhea. Cell Mol Gastroenterol Hepatol. 2018;6:33-45.

37. Bhandari SK, Xu B, Nyachoti CM, Giesting DW, Krause DO. Evaluation of alternatives to antibiotics using an Escherichia coli K88+ model of piglet diarrhea: effects on gut microbial ecology. J Anim Sci. 2008;86:836-47.

38. Giang HH, Viet TQ, Ogle B, Lindberg JE. Growth performance, digestibility, gut environment and health status in weaned piglets fed a diet supplemented with a complex of lactic acid bacteria alone or in combination with Bacillus subtilis and Saccharomyces boulardii. Livest Sci. 2012;143:132-41.

39. Turner JR. Intestinal mucosal barrier function in health and disease. Nat Rev Immunol. 2009;9:799-809.

40. Bruewer M, Luegering A, Kucharzik T, Parkos C, Madara J, Hopkins AM, et al. Proinflammatory cytokines disrupt epithelial barrier function by apoptosisindependent mechanisms. J Immunol. 2003:171:6164-72.

41. Berkes J, Viswanathan VK, Savkovic SD, Hecht G. Intestinal epithelial responses to enteric pathogens: effects on the tight junction barrier, ion transport, and inflammation. Gut. 2003;52:439-51.

42. Edelblum $\mathrm{KL}$, Turner JR. The tight junction in inflammatory disease: communication breakdown. Curr Opin Pharmacol. 2009;9:715-20.

43. Gu MJ, Song SK, Park SM, Lee IK, Yun C-H. Bacillus subtilis protects porcine intestinal barrier from deoxynivalenol via improved zonula occludens-1 expression. Asian Australas J Anim Sci. 2014;27:580-6.

44. Gong Y, Li H, Li Y. Effects of Bacillus subtilis on epithelial tight junctions of mice with inflammatory bowel disease. J Interf Cytokine Res. 2016;36:75-85.

45. Forte LR, Thorne PK, Eber SL, Krause WJ, Freeman RH, Francis SH, et al. Stimulation of intestinal $\mathrm{Cl}$ - transport by heat-stable enterotoxin: activation of CAMP-dependent protein kinase by CGMP. Am J Physiol Cell Physiol. 1992;263:c607-15

46. Thiagarajah JR, Verkman AS. CFTR pharmacology and its role in intestinal fluid secretion. Curr Opin Pharmacol. 2003;3:594-9.

47. Xie C, Tang X, Xu W, Diao R, Cai Z, Chan HC. A host defense mechanism involving CFTR-mediated bicarbonate secretion in bacterial prostatitis. PLoS One. 2010;5:e15255

48. Kim J, Khan W, Kim JJ, Khan WI. Goblet cells and mucins: role in innate defense in enteric infections. Pathogens. 2013;2:55-70.

49. Pelaseyed T, Bergström JH, Gustafsson JK, Ermund A, Birchenough GMH, Schütte $A$, et al. The mucus and mucins of the goblet cells and enterocytes provide the first defense line of the gastrointestinal tract and interact with the immune system. Immunol Rev. 2014;260:8-20.

50. Hansson GC. Role of mucus layers in gut infection and inflammation. Cuur Opin Microbiol. 2012;15:57-62.

51. Schierack P, Wieler LH, Taras D, Herwig V, Tachu B, Hlinak A, et al. Bacillus cereus var. toyoi enhanced systemic immune response in piglets. Vet Immunol Immunopathol. 2007;118:1-11.

52. Zhang W, Zhu Y, Zhou D, Wu Q, Song D, Dicksved, et al. Oral administration of a select mixture of Bacillus Probiotics affects the gut microbiota and goblet cell function following Escherichia coli challenge in newly weaned pigs of genotype MUC4 that are supposed to be enterotoxigenic E. coli F4ab/ac receptor negative. Appl Environ Microbiol. 2017:83:e02747-16.

53. Liao S, Nyachoti M. Using probiotics to improve swine gut health and nutrient utilization. Anim Nutr. 2017:3:331-43.

54. Owusu-Asiedu A, Jaworski NW, Awati AA, Stein HH. Effect of Bacillus spp. direct-fed microbial supplementation on the nutrient digestibility by weanling pigs. J Anim Sci. 2014;92(Supple 2):143.

55. Jaworski NW, Owusu-Asiedu A, Walsh MC, McCann JC, Loor JJ, Stein HH. Effects of a 3 strain Bacillus-based direct-fed microbial and dietary fiber concentration on growth performance and expression of genes related to absorption and metabolism of volatile fatty acids in weanling pigs. J Anim Sci. 2017:95:308-19.

56. Suva M, Sureja V, Kheni D. Novel insight on probiotic Bacillus subtilis: mechanism of action and clinical applications. J Curr Res Sci Med. 2016;2:65-72. 